\title{
Uji Kinerja Instalasi Daur Ulang Air Limbah Industri Kaleng di Jakarta
}

\section{Performance Test Installation of Wastewater Re-Use for Canned Industry in Jakarta}

\author{
SATMOKO YUDO, RUDI NUGROHO \\ Pusat Teknologi Lingkungan, Badan Pengkajian dan Penerapan Teknologi \\ Gedung Geostech 820 Lt.2, Kawasan Puspiptek, Tangerang Selatan, Banten 15314 \\ Email: satmoko.yudo@bppt.go.id
}

\begin{abstract}
The need for clean water consumption continues to increase in line with the current population and industry growth. The canned industry is one of the industries that consume a considerable amount of water for the production process, while the availability of clean water sources is very limited, both in quantity and quality. One alternative solution to the problem above is by building a wastewater treatment plant into reusable water (recycling) to meet the needs of the washing process in the industry. This paper discusses the testing of wastewater recycling installations into clean water in a canned industry in Jakarta. The process of recycling wastewater is divided into several stages, namely chemical processes for $\mathrm{pH}$ control, biological processes of activated sludge, biofilter, and filtration. Afterward, the wastewater is filtered using a reverse osmosis membrane. The test results show that the water quality of recycling wastewater and filtered wastewater using RO membranes could produce pure water quality. The use of water for the process in the canned industry is large enough for canned washing processes. Therefore, by using the recycling technology, the use of water, especially for the washing process, can be saved up to $100 \%$.
\end{abstract}

Keyword : wastewater reuse, reverse osmosis, can industries

\begin{abstract}
ABSTRAK
Kebutuhan akan konsumsi air bersih terus meningkat sejalan dengan pertumbuhan penduduk dan industri saat ini. Industri kaleng merupakan salah satu industri yang mengkomsumsi air dalam jumlah yang cukup banyak untuk proses produksi, sedangkan ketersediaan sumber air bersih sangat terbatas, baik secara kuantitas maupun kualitas. Salah satu alternatif solusi permasalahan di atas yaitu dengan membangun instalasi pengolahan air limbah menjadi air yang dapat digunakan kembali (daur ulang) guna memenuhi kebutuhan proses pencucian di industrinya. Makalah ini membahas tentang pengujian instalasi daur ulang air limbah menjadi air bersih di salah satu industri kaleng di Jakarta. Proses pengolahan daur ulang air limbah terbagi dalam beberapa tahap yaitu proses pengolahan air limbah produksi dengan proses kimia untuk kontrol pH, proses biologis lumpur aktif dan biofilter serta filtrasi. Kemudian berikutnya dengan proses filtrasi menggunakan membran reverse osmosis. Hasil pengujian menunjukkan bahwa kualitas air pengolahan daur ulang air limbah dan penyaringan dengan menggunakan membran $\mathrm{RO}$ menghasilkan kualitas air yang murni. Pemakaian air untuk proses di industri kaleng yang cukup besar adalah untuk proses pencucian kaleng. Sehingga dengan adanya teknologi daur ulang, maka pemakaian air khususnya untuk proses pencucian dapat dihemat sampai $100 \%$.
\end{abstract}

Kata kunci : Daur ulang air limbah, reverse osmosis, industri kaleng

\section{PENDAHULUAN}

\subsection{Latar Belakang}

Air merupakan kebutuhan yang sangat vital bagi kehidupan manusia. Karena itu jika kebutuhan akan air tersebut belum tercukupi maka akan memberikan dampak yang besar bagi manusia terutama yang berkaitan dengan masalah kesehatan, kenyamanan maupun sosial. Pengadaan air bersih di Indonesia pada umumnya masih terpusat di daerah perkotaan. Hal ini terjadi karena alasan bisnis dan komersial. Kehadiran PDAM secara nasional pada tahun 2014 jumlahnya baru mencapai $68,36 \%{ }^{(1)}$. Masyarakat maupun industri mengandalkan sumber air yang berasal dari air tanah, mata air, atau air sungai 
untuk kebutuhan air mereka. Hal ini dikarenakan jumlah air yang masih relatif sedikit dan harga jual air PDAM yang dirasa masih terlalu tinggi.

Proses produksi dalam suatu industri memerlukan air dengan persyaratan tertentu seperti untuk pembuatan steam, pencucian alatalat maupun produk serta untuk pendingin mesin. Apabila air yang digunakan untuk keperluan industri ini kualitasnya berada di bawah standar, maka dampak yang diakibatkan adalah cepat rusaknya peralatan mesin seperti nozzel dan sistem perpipaan. Oleh karena itu perlu teknologi pengolahan air yang dapat menjadikan air tanah kualitasnya setara dengan kualitas air PDAM atau bahkan setara dengan air siap minum.

Terdapat bermacam-macam cara untuk perjenihan air mulai dari penyaringan sederhana, koagulasi-flokulasi-sedimentasi, ultrafiltrasi maupun osmosis balik (Reverse Osmosis/RO) dengan menggunakan membran. Untuk keperluan pengolahan khusus, tidak semua metode diatas dapat diterapkan. Pengolahan air secara khusus seperti penggunaan resin ion exchange untuk mengambil ion-ion yang terlarut dalam air sering juga diterapkan pada industriindustri(2).

Permasalahan yang sering dihadapi yang berkaitan dengan pengadaan air untuk kebutuhan proses industri adalah kualitas sumber air tanah itu sendiri. Banyak daerah yang air tanahnya mengandung besi dan mangan yang tinggi sehingga warna air kekuningan. Selain itu juga banyak daerah dengan kondisi air tanah yang sudah terintrusi oleh air laut sehingga kadar garamnya tinggi. Ada juga daerah yang air tanahnya bersifat gambut yaitu berwarna kecoklatan dan kandungan organiknya tinggi.

Selain permasalahan kualitas, pemakaian air tanah sangat mengganggu lingkungan. Pengambilan air tanah yang intensif mengakibatkan penurunan muka tanah yang berdampak terjadinya penggenangan atau banjir pada daerah tersebut. Selain itu penurunan muka tanah juga memicu terjadinya kontaminasi air asin atau intrusi air laut ${ }^{(3)}$. Mengantisipasi hal ini Pemda DKI Jakarta akan menerbitkan Perda tentang larangan penggunaan air tanah ${ }^{(4)}$.

Sumber air yang digunakan oleh industri kaleng untuk proses industri selama ini adalah dari air sumur tanah dalam dan air bersih dari PDAM.

Kondisi kualitas air sumur tanah dalam di industri ini kurang baik yaitu bersifat gambut, kadar organiknya tinggi, keruh, dan berwarna kekuningan. Kekeruhan dan warna tersebut akan berakibat pada akumulasi lumpur di pipa maupun sistem penampungan.

Hasil analisis kualitas air tanah, Tabel 1 , menunjukkan kekeruhan, warna air, dan zat padat terlarut (TDS/Total Dissolved Solids) yang cukup tinggi dan cenderung meningkat dari waktu ke waktu. Nilai TDS sekitar $411 \mathrm{mg} / \mathrm{l}$ dalam 6 (enam) bulan meningkat menjadi $940 \mathrm{mg} / \mathrm{l}$ (payau). Karena sudah terjadi intrusi air laut sampai sekitar kawasan industri. Pemakaian air yang mengandung air laut untuk proses produksi pencucian kaleng akan mengakibatkan terjadinya kerak di pipa-pipa, nozzel dan peralatan lain ${ }^{(8)}$.

Tabel 1. Hasil analisa kualitas air tanah

\begin{tabular}{|c|c|c|c|c|c|c|}
\hline No & Parameter & $\begin{array}{l}\text { Baku } \\
\text { Mutu }\end{array}$ & \begin{tabular}{|c|} 
Hasil \\
Analisa \\
Desember \\
2006 \\
\end{tabular} & $\begin{array}{c}\text { Hasil } \\
\text { Analisa } \\
\text { Februari } \\
2007\end{array}$ & $\begin{array}{c}\text { Hasil } \\
\text { Analisa } \\
\text { Mei } 2007\end{array}$ & Satuan \\
\hline \multicolumn{7}{|c|}{ FISIKA } \\
\hline 1. & Warna & 50 & 81 & 84 & 68 & $\begin{array}{l}\text { Skala } \\
\text { TCU }\end{array}$ \\
\hline 2. & Bau & $\begin{array}{l}\text { Tidak } \\
\text { berbau }\end{array}$ & Tidak berbau & Tidak berbau & Tidak berbau & - \\
\hline 3. & Rasa & $\begin{array}{c}\text { Tidak } \\
\text { berasa }\end{array}$ & Tidak berasa & Tidak berasa & Payau & - \\
\hline 4. & Kekeruhan & 25 & 1,26 & 1 & 1 & $\begin{array}{l}\text { Skala } \\
\text { NTU }\end{array}$ \\
\hline 5. & $\begin{array}{l}\text { Zat Padat Terlarut } \\
\text { (TDS) }\end{array}$ & 1500 & 411 & 540 & 940 & $\mathrm{mg} / \mathrm{I}$ \\
\hline \multicolumn{7}{|c|}{ KIMIA } \\
\hline 6. & Zat Organik & 10 & 18,69 & 12,64 & 14,22 & $\mathrm{mg} / \mathrm{l}$ \\
\hline 7. & pH & $\begin{array}{c}6,5- \\
8,5\end{array}$ & 8,1 & 7,45 & 8,12 & - \\
\hline 8. & Kesadahan Total & 500 & 212,00 & 284,00 & 421,00 & $\mathrm{mg} / \mathrm{l}$ \\
\hline 9. & Besi & 1 & 0,34 & 0,4 & 0,36 & $\mathrm{mg} / \mathrm{l}$ \\
\hline 10. & Mangan & 0,5 & 0,21 & 0,15 & 0,1 & $\mathrm{mg} / \mathrm{l}$ \\
\hline 11. & Sulfat & 400 & 32,6 & 35,3 & 51,59 & $\mathrm{mg} / \mathrm{l}$ \\
\hline 12. & Nirit & 1 & 0,08 & 0,06 & 0,13 & $\mathrm{mg} / \mathrm{l}$ \\
\hline
\end{tabular}

Baku mutu sesuai Peraturan Menteri Kesehatan RI Nomor 32 Tahun 2017(16)

Industri kaleng ini menghadapi permasalahan dengan tidak adanya jalur perpipaan yang memadai dari PDAM sehingga suplai air dilakukan melalui truk tangki ke lokasi pabrik. Selain biaya pemakaian air bersih dari PDAM juga biaya untuk pengiriman dengan truk berkali-kali dalam setiap hari.

Pemakaian air untuk proses di industri kaleng yang cukup besar adalah untuk proses pencucian kaleng (can washer) yang sudah dicetak. Proses ini untuk mencuci dan membilas bagian dalam dan luar kaleng dari lube oil, garam, cup lube, coolant dan gemuk yang datang dari mesin sebelumnya ${ }^{(6)}$. Terdapat 4 line proses washer secara pararel bekerja, masing-masing line proses membutuhkan air $175 \mathrm{~m}^{3} /$ hari sehingga total kebutuhan air bersih sebesar $700-800 \mathrm{~m}^{3} /$ hari (Gambar 2).

Salah satu alternatif untuk solusi permasalahan di atas yaitu dengan menerapkan teknologi daur ulang air limbah di industri yang dapat mengolah air limbah produksi menjadi air yang dapat digunakan kembali (daur ulang) untuk mencukupi kebutuhan proses produksi di industrinya. Selain itu penggunaan kembali atau daur ulang air limbah dipastikan akan lebih menguntungkan dari sisi finansial maupun lingkungan ${ }^{(5)}$. 
Makalah ini menjelaskan hasil uji kinerja instalasi daur ulang air limbah sebagai sumber air untuk proses produksi di salah satu industri pembuatan kaleng.

\section{BAHAN DAN METODE}

\subsection{Lokasi unit daur ulang}

Lokasi penelitian di pabrik kaleng PT. United Can Ltd, Jl. Daan Mogot KM 17, Kalideres, DKI Jakarta. Kapasitas unit daur ulang air limbah terdiri dari kapasitas produksi air bersih sebesar $700 \mathrm{~m}^{3} /$ hari dan kapasitas produksi air RO (Reverse Osmosis) sebesar $200 \mathrm{~m}^{3} /$ hari.

\subsection{Bahan}

Data-data sekunder tentang sumber air, neraca air dan kualitas air. Data deskripsi tentang proses industri dan proses pengolahan air limbah. Data primer kualitas air hasil pengambilan sampling di beberapa titik.

\subsection{Metodologi}

Metodologi yang digunakan adalah metode analisis data primer dan sekunder, telaah pustaka, dan survey lapangan. Data primer berupa hasil analisa sampel kualitas air di beberapa titik, yaitu di inlet instalasi pengolahan air limbah, outlet unit daur ulang air limbah dan outlet unit filtrasi membran RO.

\subsection{Proses Pengolahan Air Limbah Menjadi Air Daur Ulang}

Proses pengolahan air limbah produksi di industri kaleng menggunakan teknologi proses biologis lumpur aktif, biofilter, proses koagulasi flokulasi, proses filtrasi, dan proses pemurnian dengan RO. Air limbah dari line produksi dipompa ke penampungan/equalisasi di IPAL. Selanjutnya air ini dicampur dengan olahan air limbah domestik dan sebagian air tanah untuk di proses lebih lanjut. Dari penampungan equalisasi ini air limbah dinetralkan $\mathrm{pH}$ nya oleh $\mathrm{pH}$ kontrol untuk selanjutnya dialirkan ke bak pengendapan awal. Lumpur yang mengendap di bak pengendapan awal dipompa ke unit pengolahan lumpur sedangkan airnya mengalir secara gravitasi ke bak aerasi lumpur aktif. Bak aerasi dilengkapi dengan sistem supply udara menggunakan 3 buah blower udara. Di bak aerasi diisi dengan lumpur aktif supaya polutan organik yang terkandung dalam air limbah di uraikan oleh mikroorganisme aerob menjadi senyawa yang lebih sederhana dan stabil seperti $\mathrm{CO}_{2}$ dan $\mathrm{H}_{2} \mathrm{O}$. Campuran air limbah dan mikroorganisme selanjutnya mengalir ke bak pengendap akhir untuk dipisahkan antara lumpur mikroba dan air. Lumpur sebagian dikembalikan ke bak aerasi dan sisanya dipompa ke unit pengolahan lumpur.

Air limbah dari bak pengendap akhir selanjutnya mengalir ke bak biofilter lanjutan. $\mathrm{Di}$ bak ini sisa lumpur yang terikut akan tersaring dan juga akan lebih menyempurnakan degradasi polutan organik. Bak biofilter lanjutan ini juga dilengkapi dengan sistem supply udara yang dialirkan dari blower udara yang ada di bak aerasi lumpur aktif. Air dari bak biofilter lanjutan ini mengalir ke bak antara 1. Bak antara 1 ini juga dipakai untuk menampung air hujan. Campuran air limbah dan air hujan di bak antara ini dipompa ke tangki pencampur (mixing tank 2) untuk dicampur dengan bahan kimia koagulan dan flokulan. Dari tangki pencampur selanjutnya air mengalir turun ke bak flokulator selanjutnya ke bak pengendapan kimia.

Bak pengendapan kimia dilengkapi dengan lamela settler untuk lebih menyempurnakan proses pengendapan. Lumpur kimia yang posisinya di bawah lamela settler secara kontinyu dipompa ke unit pengolah lumpur. $\mathrm{Di}$ proses penanganan lumpur terdiri dari empat unit utama yaitu penampungan lumpur, thickener, filter press, dan bak pengering lumpur. Campuran lumpur dan air dari bak pengendap awal, bak pengendap akhir, dan bak pengendapan kimia ditampung dalam bak penampung lumpur. Bak ini dilengkapi dengan sensor level yang menggerakkan pompa bila tangki penuh. Dari penampung lumpur selanjutnya dipompa ke unit pemekat lumpur sambil didosing menggunakan flokulan. Lumpur yang mengendap di pemekat lumpur ini selanjutnya di pompa ke bak pengering lumpur sedangkan airnya yang berada di bagian atas akan mengalir overflow ke penampungan tirisan lumpur. Lumpur di bak pengering lumpur akan tersaring, airnya meresap ke bawah menuju bak tirisan lumpur sedangkan lumpurnya akan tertahan di bak dan dibiarkan sampai kering. Bila bak penampung ini sudah tidak sanggup lagi menampung lumpur maka sebagian lumpur di saring dengan filter press, lumpurnya tertahan di filter dan airnya mengalir jatuh ke bak penampungan tirisan lumpur. Air yang tertampung dalam bak penampungan lumpur ini secara kontinyu dipompa di kembalikan ke bak equalisasi.

Air limbah yang telah diproses secara kimiawi dan dipisahkan endapannya di bak pengendapan kimia selanjutnya mengalir ke bak antara 2. Dari bak antara 2 ini, air dipompa ke unit filter yang terdiri dari filter pasir, filter mangan, filter karbon dan softener. Setelah air melalui ke empat filter ini selanjutnya keluar dan di tampung sebagai produk air bersih di bak penampung air bersih. Filter pasir fungsinya untuk menyaring padatan tersuspensi yang kemungkinan masih 
terikut di air setelah proses pengendapan kimia. Dari bak penampung air bersih air dipompa ke unit produksi kaleng untuk dipergunakan sebagai air washer. Sebagian dari air di bak penampung air bersih ini dipompa untuk diproses menggunakan membran Reverse Osmosis dan selanjutnya di tampung dalam bak penampung air RO. Air produk RO ini secara kontinyu dipompa ke unit DI di dalam pabrik. Diagram proses daur ulang air limbah secara lengkap dapat dilihat pada Gambar 1.

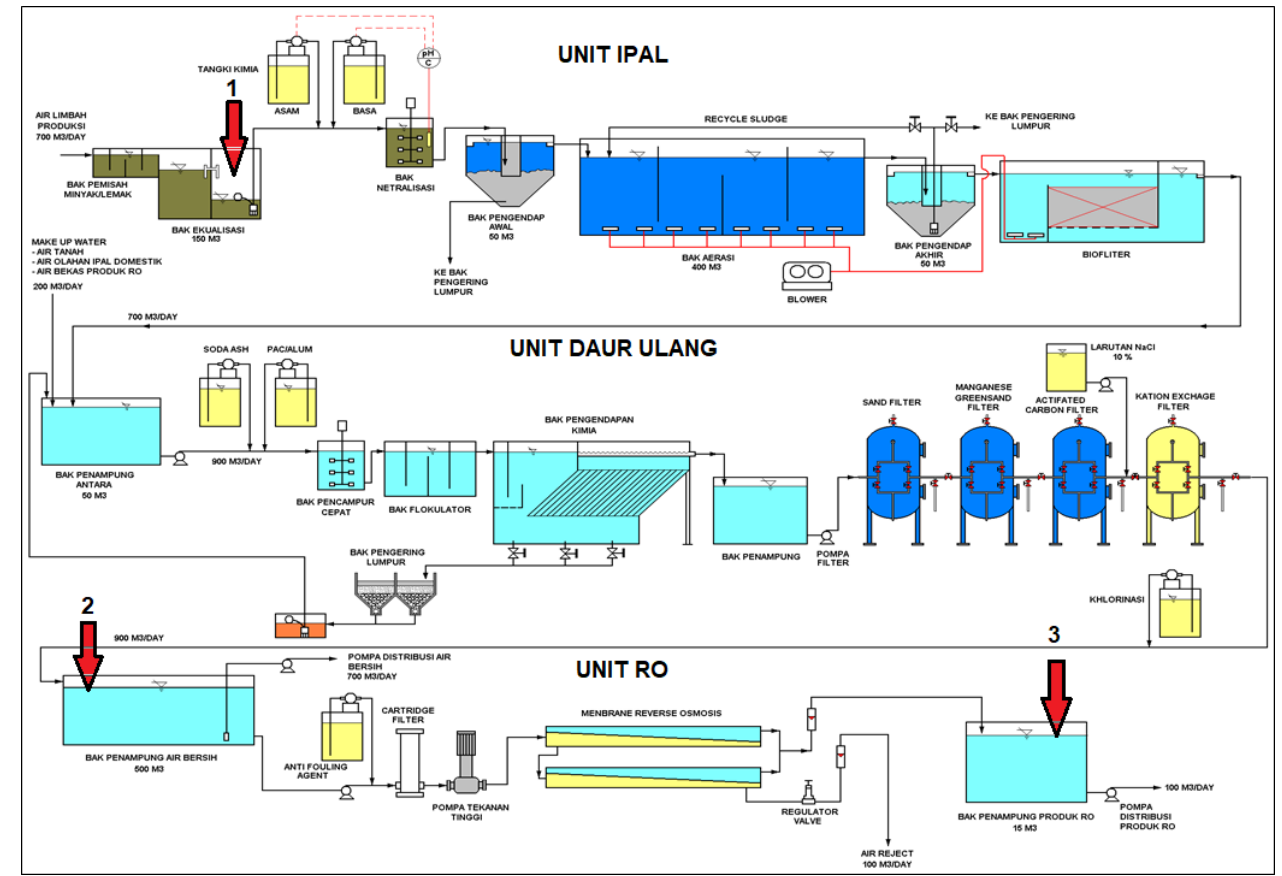

Gambar 1. Flow Diagram Proses Pengolahan Air Limbah Produksi Menjadi Air Daur Ulang dan Lokasi Pengambilan Sample

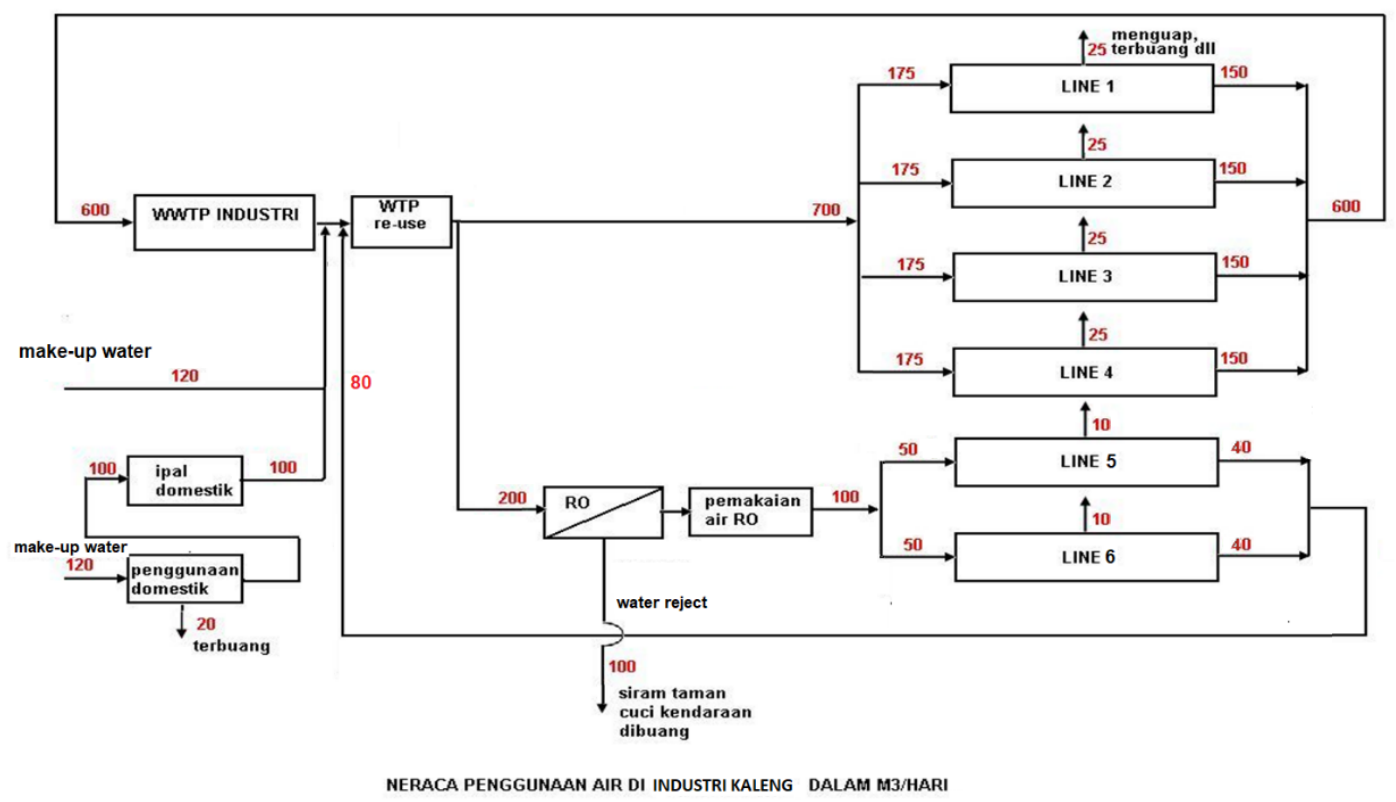

Gambar 2. Neraca Air di Industri Kaleng untuk Perencanaan Instalasi Air Daur Ulang

\section{HASIL DAN PEMBAHASAN}

\subsection{Hasil Analisa Data Sampling}

Dalam memantau kualitas air dari hasil olahan daur ulang yang akan digunakan untuk proses industri, maka data kualitas air $\mathrm{RO}$ yang dihasilkan harus selalu dicatat untuk mengecek kualitas air sesuai dengan yang dipersyaratkan. 
Analisa dilakukan selama 61 (enam puluh satu) hari dan pengambilan sampel yang akan diuji dilakukan di 3 (tiga) titik yaitu di bagian Inlet yang diambil di bak ekualisasi, di outlet air bersih unit daur ulang, dan air produk RO. Analisa dilakukan terhadap beberapa parameter antara lain kekeruhan (turbidity), Total Suspended Solids (TSS), pH, sulfat, sulfida, kesadahan, dan zat organik. Hasil analisis akan dijelaskan sebagai berikut.

\section{a. Zat Organik $\left(\mathrm{KMnO}_{4}\right)$}

Pada gambar 3. terlihat penurunan konsentrasi zat organik setelah melalui unit IPAL dan unit daur ulang dari rata-rata $92,20 \mathrm{mg} / \mathrm{l}$ turun menjadi rata-rata $53,12 \mathrm{mg} / \mathrm{l}$ dan nilai ini dibawah nilai baku mutu air limbah menurut Peraturan Gubernur Provinsi DKI Jakarta Nomor 69 Tahun 2013, yaitu $85 \mathrm{mg} / \mathrm{l}^{(10)}$. Efisiensi penurunan zat organik minimal $15,32 \%$ dan maksimal $69,57 \%$ dengan rata-rata $44,78 \%$. Sedangkan konsentrasi zat organik setelah melalui unit $\mathrm{RO}$ nilainya menjadi $0 \mathrm{mg} / \mathrm{l}$ dibawah nilai baku mutu untuk air minum yaitu $10 \mathrm{mg} / \mathrm{I}^{(12)}$.

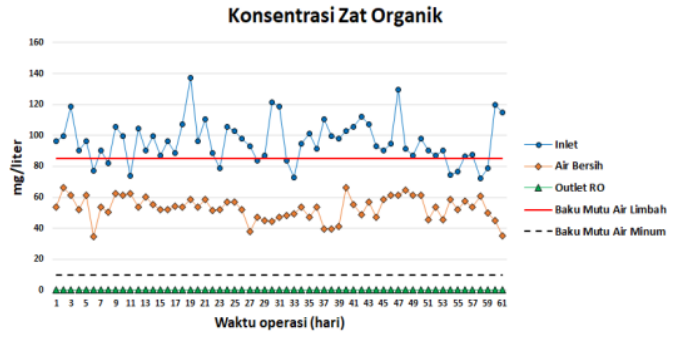

Gambar 3. Konsentrasi zat organik di inlet IPAL, outlet daur ulang dan outlet RO

\section{b. Total Suspended Solid (TSS)}

Seperti terlihat pada Gambar 4 konsentrasi TSS dalam air limbah cukup tinggi dengan nilai maksimum $426 \mathrm{mg} / \mathrm{l}$ dan minimum $62 \mathrm{mg} / \mathrm{l}$ dengan rata-rata $219,51 \mathrm{mg} / \mathrm{l}$ diatas baku mutu air limbah $\left(100 \mathrm{mg} / \mathrm{l}^{(13)}\right.$. Setelah diproses melalui IPAL dan unit daur ulang konsentrasi TSS turun drastis menjadi rata-rata $1,43 \mathrm{mg} / \mathrm{l}$.

Penurunan konsentrasi TSS tersebut menunjukan adanya peran mikroba dalam proses bioflokulasi, sehingga terjadi suatu sedimentasi yang efisien ${ }^{(14)}$.

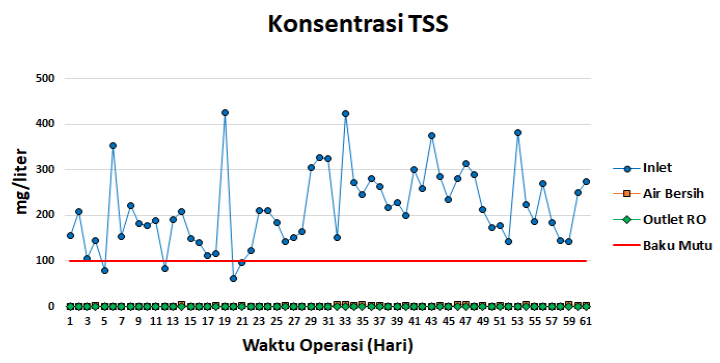

Gambar 4. Konsentrasi TSS di inlet IPAL, outlet daur ulang dan outlet $\mathrm{RO}$

\section{c. Kekeruhan (Turbididty)}

Kualitas estetika air hasil daur ulang ditingkatkan dengan menghilangkan kekeruhan ${ }^{(15)}$. Hasil pengambilan sampel di titik inlet dan outlet daur ulang seperti terlihat pada Gambar 5, menunjukkan rata-rata konsentrasi kekeruhan mengalami penurunan dari 203,12 $\mathrm{mg} / \mathrm{l}$ menjadi $3,14 \mathrm{mg} / \mathrm{l}$ dengan efisiensi rata-rata $98,45 \%$.

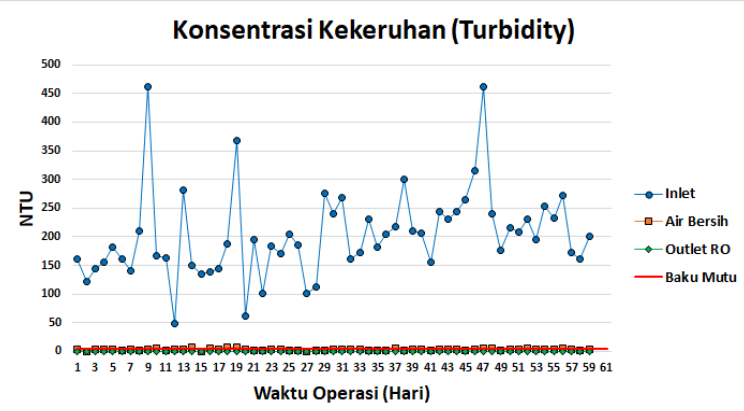

Gambar 5. Konsentrasi kekeruhan di inlet IPAL, outlet daur ulang dan outlet $\mathrm{RO}$

\section{d. Derajat Keasaman (pH)}

Pada gambar 6 terlihat nilai $\mathrm{pH}$ air limbah di bak ekualisasi sebelum diolah. Nilai $\mathrm{pH}$ rata-rata setelah diolah IPAL menunjukkan 5,05 dan melalui unit daur ulang $\mathrm{pH}$ meningkat menjadi rata-rata 6,66 . Nilai $\mathrm{pH}$ ini memenuhi baku mutu persyaratan sebagai air bersih ${ }^{(14)}$. Setelah melalui proses $\mathrm{RO}$ nilai $\mathrm{pH}$ menurun menjadi rata-rata 6,13 . Penurunan $\mathrm{pH}$ ini akibat proses membran RO menghilangkan senyawa organik dan anorganik, namun gas $\mathrm{CO}_{2}$ bergabung dengan ion $\mathrm{OH}$ - bebas dalam air untuk membentuk $\mathrm{HCO}_{3}$ yang asam ${ }^{(17)}$. Meskipun demikian nilai $\mathrm{pH}$ ini masuk kedalam persyaratan mutu air minum dalam kemasan (air demineral) ${ }^{(18)}$.

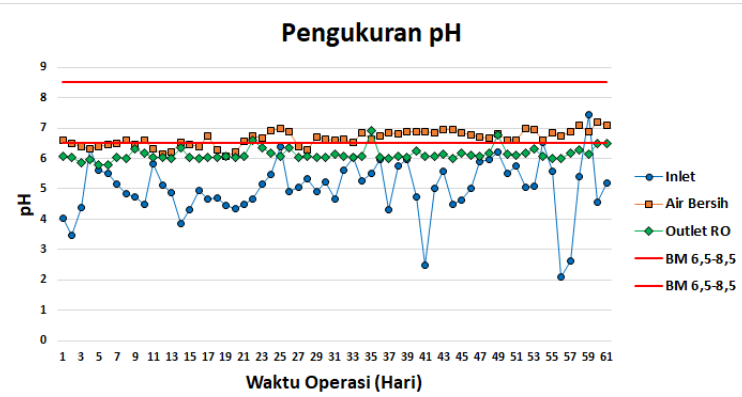

Gambar 6. Nilai pH di inlet IPAL, outlet Daur Ulang dan outlet $\mathrm{RO}$

\section{e. Konduktivitas}

Konsentrasi konduktivitas atau daya hantar listrik (DHL) yang tinggi pada air menunjukan air tersebut mengandung mineral tinggi. Kadar mineral dalam air dapat menyebabkan kerak ataupun korosi pada kaleng. Gambar 7. 
menunjukkan bahwa konsentrasi konduktivitas meningkat setelah dilakukan pengolahan air limbah dengan rata-rata $10,8 \%$. Kenaikan ini disebabkan karena penambahan bahan kimia untuk proses koagulan ${ }^{(19)}$. Konsentrasi konduktivitas air turun drastis dari rata-rata 1.458 $\mu \mathrm{S} / \mathrm{cm}$ menjadi rata-rata $10,13 \mu \mathrm{S} / \mathrm{cm}$ setelah melalui proses $\mathrm{RO}$.

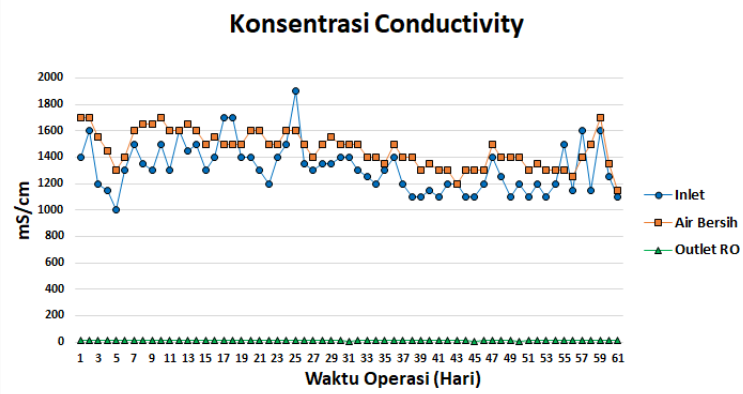

Gambar 7. Konsentrasi TSS di inlet IPAL, Outlet Daur Ulang dan Outlet $\mathrm{RO}$

\section{f. Sulfat}

Sulfat dalam kondisi anaerob (dalam air buangan) menghasilkan $\mathrm{H}_{2} \mathrm{~S}$ yang menyebabkan bau dan jika kontak dengan udara $\left(\mathrm{O}_{2}\right)$ dapat menyebabkan korosi pada perpipaan. Sulfat pada boilers dapat menimbulkan endapan (hard scales) demikian pula pada heat exchanger ${ }^{(20)}$.

Gambar 8 menunjukkan hasil analisa bahwa konsentrasi sulfat pada inlet IPAL rata-rata 505,33 $\mathrm{mg} / \mathrm{l}$, setelah melalui proses pengolahan air limbah dan daur ulang konsentrasi sulfat turun menjadi rata-rata $388,67 \mathrm{mg} / \mathrm{l}$. Nilai ini masih dibawah baku mutu air bersih Permenkes ${ }^{(16)}(400$ $\mathrm{mg} / \mathrm{l})$.

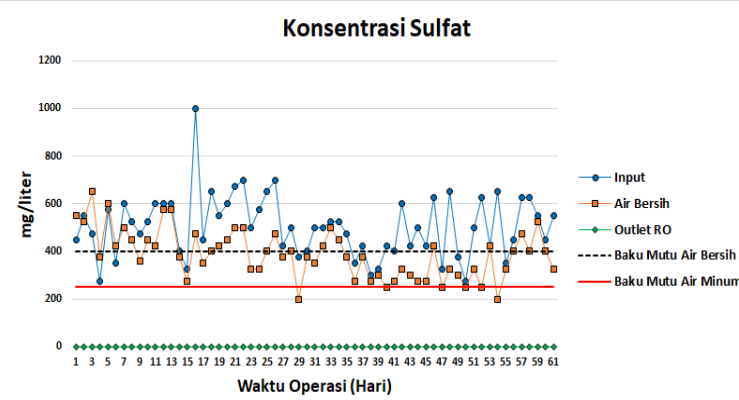

Gambar 8. Konsentrasi sulfat di inlet IPAL, outlet daur ulang dan outlet $\mathrm{RO}$

\section{g. Sulfida}

Dalam proses industri, keberadaan sulfida dalam bentuk hidrogen sulfida sangat mengganggu karena dapat menyebabkan kerusakan pada beton-beton dan juga berkaratnya logam-logam (pipa penyaluran)(21).

Gambar 9 menunjukkan konsentrasi sulfida air limbah rata-rata $0,156 \mathrm{mg} / \mathrm{l}$ dapat diturunkan menjadi rata-rata $0,002 \mathrm{mg} / \mathrm{l}$ setelah melalui IPAL dan unit daur ulang. Nilai ini jauh dibawah baku mutu air limbah yang dikeluarkan oleh PerGub DKI Jakarta Nomor 69 Tahun 2013 ${ }^{(11)}$.

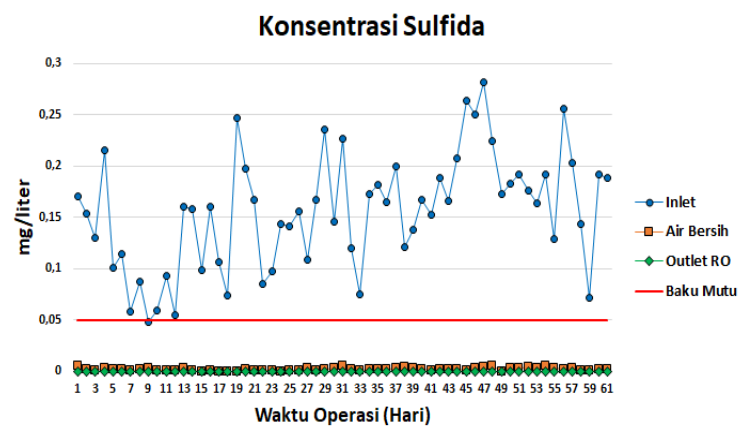

Gambar 9. Konsentrasi Sulfida di inlet IPAL, Outlet Daur Ulang dan Outlet RO

\section{h. Kesadahan}

Kesadahan dalam air sangat tidak dikehendaki untuk pemakaian air di industri, karena unsur kalsium (Ca) dan magnesium $(\mathrm{Mg})$ dapat menyebabkan kerak pada dinding peralatan sistem pemanasan sehingga dapat menyebabkan kerusakan pada peralatan dan perpipaan di industri ${ }^{(10)}$. Pada umumnya untuk pemakaian air khususnya untuk air proses industri jumlah kesadahan harus 0 (nol), bila tidak harus diolah terlebih dahulu untuk mengurangi nilai kesadahannya(22). Proses pengolahan air sadah dapat dilakukan dengan membran tanpa dilakukan bahan-bahan kimia ${ }^{(23)}$.

Hasil analisa sampling (Gambar 10) menunjukkan nilai rata-rata konsentrasi kesadahan dari inlet air limbah $35 \mathrm{mg} / \mathrm{l}$, setelah melalui pengolahan air limbah (IPAL) dan daur ulang nilai rata-rata kesadahan turun menjadi 27 $\mathrm{mg} / \mathrm{l}$ dan nilai kesadahan di outlet $\mathrm{RO}$ menjadi $0,00 \mathrm{mg} / \mathrm{l}$. Konsentrasi kesadahan hasil pengolahan hasil proses $\mathrm{RO}$ dan unit daur ulang masuk kedalam tingkat kesadahan air lunak ${ }^{(24)}$.

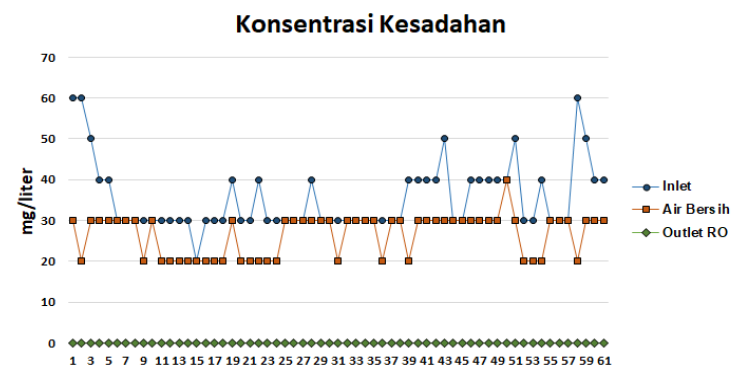

Gambar 10. Konsentrasi kesadahan di inlet IPAL, outlet daur ulang dan outlet $\mathrm{RO}$ 


\subsection{Hasil proses daur ulang}

Proses pengolahan air limbah produksi menjadi air daur ulang di industri kaleng ini menggunakan teknologi proses biologi lumpur aktif, biofilter, proses koagulasi, flokulasi, proses filtrasi, dan proses pemurnian dengan RO. Kombinasi proses tersebut dapat mengolah air limbah sampai menghasilkan air olahan dengan kualitas sebagai air minum ${ }^{(9)}$.

Air baku yang berasal dari proses produksi pertama-tama ditampung dalam bak penampung yang berfungsi sebagai equalisasi. Dari $800 \mathrm{~m}^{3}$ air yang dipakai proses untuk 6 line di 2 Pc, diperkirakan hanya sekitar $600 \mathrm{~m}^{3}$ yang dapat diolah dan sisanya terbuang di proses produksi.

Air hasil pengolahan limbah produksi selanjutnya ditampung dalam tangki penampung antara yang terbuat dari fiber. Volume tangki penampung ini total $50 \mathrm{~m}^{3}$. Air yang ditampung di tangki penampung ini selain air hasil olahan IPAL produksi juga ditambahkan air tanah dan air hasil olahan IPAL domestik seperti yang terlihat dalam neraca air (Gambar 2). Penambahan ini dimaksudkan agar produk akhir air untuk proses di industri dapat mencapai 800 $\mathrm{m}^{3}$ per hari.

Gambar 3 menjelaskan bahwa air outlet dari proses IPAL ditampung di bak penampung di mana air tersebut masih terdapat warna, bau dan kandungan polutan lain seperti logam, selanjutnya di proses secara kimia dan fisika dengan pengendapan. Di dalam proses kimia fisika ini, bahan kimia penggumpal dan pembentuk flok ditambahkan. Flok akan mengendap di bak pengendap. Bak pengendap dilengkapi dengan lamela settler agar proses pengendapan lebih sempurna. Endapan sewaktu-waktu di drain kemudian dialirkan ke bak pengering lumpur. Air dari bak pengendap selanjutnya ditampung ke bak penampung antara yang berfungsi juga sebagai bak penampung umpan untuk proses berikutnya.

Dari bak penampung antara selanjutnya air dipompakan melalui filter pasir, filter manganese greensand dan filter karbon dengan menggunakan pompa centrifugal multistage. Filter-filter ini berfungsi untuk menurunkan padatan tersuspensi yang kemungkinan masih belum terendapkan sempurna di bak pengendap, mereduksi warna yang masih tersisa dan menyerap logam seperti besi (Fe) dan mangan $(\mathrm{Mn})$ yang belum terendapkan. Dari filter-filter ini selanjutnya air dialirkan melalui filter penurun kesadahan dengan media filternya berupa resin cation exchange ${ }^{(10)}$. Apabila kondisi filter ini dinyatakan jenuh akan dilakukan regenerasi dengan menggunakan larutan natrium khlorida $(\mathrm{NaCL})$.

Air dari filter sudah jernih tidak berbau dan kandungan polutan organik COD (Chemical Oxygen Demand) sudah di bawah 20 ppm dan kesadahan di bawah 20 ppm. Namun, kandungan garam terlarut dan konduktifitas masih tinggi yang kadarnya hampir sama seperti di air baku. Keluar dari filter, air ditampung dalam bak penampungan air bersih sambil diinjeksi khlorin untuk desinfektan. Bak penampungan air bersih dibuat besar yaitu $400 \mathrm{~m}^{3}$, agar supaya cadangan air aman apabila sewaktu-waktu terjadi kendala di proses. Air ini sudah dapat digunakan untuk proses pencucian di produksi kaleng. Air dari bak penampungan ini sebanyak $200 \mathrm{~m}^{3}$ per hari dialirkan ke proses $\mathrm{RO}$, dan 700 $\mathrm{m}^{3}$ per hari dialirkan ke line 1 sampai line $4 \mathrm{di}$ pabrik dengan menggunakan pompa.

Sebelum melewati proses $\mathrm{RO}$, air terlebih dahulu di filter dengan cartridge filter ukuran 5 10 mikron. Tujuan filter ini adalah agar membran RO tidak cepat rusak karena penyumbatan partikel halus. Membran RO yang digunakan adalah jenis TFC (Thin Film Compossite) Brackish water (air payau) dengan tekanan sampai dengan 20 bar. Product recovery pada sistem RO diatur sebesar 50\% agar menghasilkan air buangan (water reject) sebesar $100 \mathrm{~m}^{3}$ per hari. Air buangan dipakai untuk mencuci lantai, siram taman, atau dibuang ke lingkungan. Air produk RO sebanyak $100 \mathrm{~m}^{3}$ per hari dengan kandungan garamnya yang sudah sangat rendah yaitu dibawah $50 \mathrm{ppm}$ dan konduktifitas dibawah 50 mikromosh.

Air produk ini selanjutnya ditampung ke bak penampung produk RO untuk didistribusikan ke unit proses produksi yang memerlukan air dengan kemurnian tinggi di line 5 dan line 6 seperti terlihat pada Gambar 2.

\section{KESIMPULAN}

Permasalahan keterbatasan dan kualitas sumber air yang digunakan untuk proses produksi industri khususnya untuk pencucian kaleng dapat diatasi dengan menerapkan teknologi daur ulang air limbah dikombinasikan dengan IPAL sistem Biofilter. Hasil analisa menunjukkan bahwa kualitas air hasil olahan unit daur ulang air limbah telah memenuhi persyaratan baku mutu air bersih dan setelah ditingkatkan kualitasnya dengan menggunakan proses $\mathrm{RO}$ dan hasil olahannya setara air murni. 


\section{PERSANTUNAN}

Ucapan terimakasih disampaikan kepada pimpinan beserta manajemen industri kaleng PT. United Can Ltd. yang telah mengaplikasikan hasil disain teknologi daur ulang air limbah peneliti BPPT. Terimakasih juga disampaikan kepada Direktur beserta para peneliti Pusat Teknologi Lingkungan-BPPT yang telah mendukung kegiatan ini.

\section{DAFTAR PUSTAKA}

1. Ahyar, A. (2017). Peningkatan Kapasitas Penyelenggara SPAM, Musyawarah Antar Perusahaan Air Minum Tingkat Nasional (MAPAMNAS) XIII Perpamsi, Direktorat Pengembangan Sistem Penyediaan Air Minum, Jakarta.

2. Cahyana, G. H. (2010). Variasi Teknologi Pengurangan Kesadahan Dalam Pengolahan Air Minum. Jurnal Sosioteknologi Terapan, Vol. XV Maret 2010, hal. 39-49.

3. Rejekiningrum, P. (2009). Peluang Pemanfaatan Air Tanah Untuk Keberlanjutan Sumber Daya Air. Jurnal Sumberdaya Lahan Vol.3, No.2. hal.85-95. Balai Penelitian Agroklimat dan Hidrologi.

4. Anonimous, (2018). Pemprov DKI Jakarta Akan Terbitkan Perda Larangan Penggunaan Air Tanah. Available from: https://metro.sindonews.com/read/1289849/ 171/pemprov-dki-akan-terbitkan-perdalarangan-penggunaan-air-tanah1521088283

5. Yudo, S. \& Hernaningsih, T. (2010). Pemilihan Teknologi Daur Ulang Air Limbah Domestik di Kantor BPPT. Jurnal Air Indonesia, Vol. 6, No. 2. 114-123. BPPT, Jakarta.

6. Santa, H. (2014). Perbaikan Kualitas Produk Can Body 330 ml Pada Departemen Two Piece Can PT United Can Co. Ltd. Dengan Menggunakan Metode Six Sigma DMAIC. Tugas Akhir Program Studi Teknik Industri, Fakultas Industri Universitas Mercu Buana, Jakarta.

7. Oktaviyanto, T. (2015). Laporan Praktek Kerja; Pembuatan Kaleng Two Pieces di PT. UCC. Program Studi Teknik Industri, Fakultas Teknik Universitas Mercu Buana, Jakarta.

8. Suharso dan Buhani, (2015). Buku Penanggulangan Kerak, Edisi 2. Graha IImu, Yogyakarta. Buku ISBN 978-602-262-509-4

9. Ikbal, Yudo, S. (2017). Desain Instalasi Daur Ulang Air di Industri Migas Studi Kasus
Kilang Minyak RU-VI Balongan, PT. Pertamina (Persero). Buku Bunga Rampai Teknologi Lingkungan, BPPT Press, Jakarta.

10. Said, N.I. (2008). Teknologi Pengolahan Air Minum. Bab 9. Penghilangan Kesadahan Dalam Air Minum. Buku Pusat Teknologi Lingkungan, BPPT, Jakarta.

11. Peraturan Gubernur Provinsi DKI Jakarta Nomor 69 Tahun 2013 Tentang Baku Mutu Air Limbah Bagi Kegiatan Dan/Atau Usaha.

12. Peraturan Menteri Kesehatan Republik Indonesia Nomor 492/Menkes/Per/IV/ 2010 Tentang Persyaratan Kualitas Air Minum.

13. Peraturan Menteri Lingkungan Hidup Republik Indonesia Nomor 5 Tahun 2014 tentang Baku Mutu Air Limbah.

14. Komarawidjaya, W. (2007). Peran Mikroba Aerob dalam Pengolahan Limbah Cair Tekstil. Jurnal Teknologi Lingkungan, Vol. 8, No. 3, hal. 223-228. BPPT, Jakarta.

15. Said, N.I. (2006). Daur Ulang Air Limbah (Water Recycle) Ditinjau Dari Aspek Teknologi, Lingkungan dan Ekonomi. Jurnal Air Indonesia, Vol. 2, No. 2 Nopember 2006, Hal.: 100-131.

16. Peraturan Menteri Kesehatan Republik Indonesia Nomor 32 Tahun 2017 tentang Standar Baku Mutu Kesehatan Lingkungan dan Persyaratan Kesehatan Air Untuk Keperluan Higiene Sanitasi, Kolam Renang, Solus Per Aqua, dan Pemandian Umum.

17. Anonimous, (2013). Reverse Osmosis Water and $\mathrm{pH}$. FilterWater.com, available from : https://www.filterwater.com/t-reverseosmosis-water-and-ph.aspx

18. Standar Nasional Indonesia. (2015). Air Demineral. SNI Nomor: 6241:2015. Badan Standarisasi Nasional.

19. Azamia, M. (2012). Skripsi Pengolahan Limbah Cair Laboratorium Kimia Dalam Penurunan Kadar Organik serta Logam Berat $\mathrm{Fe}, \mathrm{Mn}, \mathrm{Cr}$ dengan Metode Koagulasi dan Adsorpsi. Program Studi Kimia, Fakultas Matematika dan Ilmu Penegtahuan Alam, Universitas Indonesia.

20. Slamet, Soemirat, J. (2004). Buku Kesehatan Lingkungan. Cetakan ke-enam, Gajah Mada Universitity Press, Yogyakarta.

21. Purba, K. (2009). Analisa Kadar Total Suspended Solid (TSS), Amoniak $\left(\mathrm{NH}^{3}\right)$, Sianida $\left(\mathrm{CN}^{-}\right)$dan Sulfida $\left(\mathrm{S}^{2-}\right)$ Pada Limbah 
Cair Bapedaldasu. Departemen Kimia, Program Studi Diploma-3 Kimia Analis Fakultas MIPA Sumatera Utara Medan.

22. Marsidi, R. (2001). Zeolit Untuk Mengurangi Kesadahan Air. Jurnal Teknologi Lingkungan, Vol. 2, No. 1. Hal:1-10, BPPT.

23. Siringoringo, F.H.D.T. (2015). Teknologi Pengolahan Air Sadah. Jurusan Teknik Kimia, Fakultas Industri, Institut Teknologi Bandung. Available from: https://www.researchgate.net/publication/28 7583207_Teknologi_Pengolahan_Air_Sada $\mathrm{h}$

24. Anonimous, (1986). Quality Criteria for Water 1986. US Environment Protection Agency, Washington, DC 
